\title{
Elastic Properties of the Fabric Liner and Their Influence on the Wear Depth of the Spherical Plain Bearing
}

\author{
Xuejin Shen, Pandong Gao, Zhaolei Liu, and Xiaoyang Chen \\ Department of Mechanical Automation Engineering, Shanghai University, Shanghai 200072, China \\ Correspondence should be addressed to Xuejin Shen; shenxuejin@gmail.com
}

Received 20 December 2013; Accepted 3 February 2014; Published 17 March 2014

Academic Editor: Yongsheng Zhang

Copyright ( 2014 Xuejin Shen et al. This is an open access article distributed under the Creative Commons Attribution License, which permits unrestricted use, distribution, and reproduction in any medium, provided the original work is properly cited.

\begin{abstract}
The major failure mechanism of typical spherical plain bearings with self-lubrication is the wear of the woven fabric liner, which is an orthotropic composite of different elastic properties in different directions. The elastic properties of the liner are required for studying the tribological properties of the spherical plain bearings. This paper aims to develop an elastic property analysis model suitable for three commonly used fabric liners through a theoretical analysis of the elastic properties in order to obtain the parameter expression of the compliance matrix. The influence of the elastic properties on the wear depth of the spherical plain bearings is further investigated. Suggestions are made for the optimal design of the spherical plain bearings based on wear reduction.
\end{abstract}

\section{Introduction}

Spherical plain bearing with self-lubricating is a kind of sliding bearings with low-speed multiaxial rotary oscillating motion pattern. Widely used in mining and metallurgy, aerospace, tank cannon gun system, and so forth $[1,2]$, the typical spherical plain bearing with self-lubricating consists of an inner ring with an outside spherical surface and an outer ring which has an inner sphere surface with a woven fabric liner bonded to it, and its main failure form is the wear of the woven fabric liner. The current studies on woven fabric liner of spherical plain bearing with self-lubricating largely concern the aspect of friction and wear experiments [3, 4], while the elastic properties are obtained mainly by tensile test experiments $[5,6]$ or numerical experiments [7-9]. Most of the experiments focus on the particular structure of the woven fabric liners [10-14]. Obtaining the elastic properties of the liner is essential in studying the mechanical properties of spherical plain bearings. The study on the influence of the elastic properties of woven fabric liners on the wear depth of the spherical plain bearings is almost blank. The purposes of this paper are to create an elastic properties analysis model which is suitable for the three commonly used woven fabric liners, to obtain the elastic properties of the plain and stain liners using the method of the tensile test experiment, and then to validate the analysis model in an experimental way and to investigate the influence of the elastic properties on the wear depth of the spherical plain bearings. We wish to propose some suggestions for liner structural optimizing.

\section{Theoretical Analysis of Elastic Properties of the Liner}

2.1. Geometric Model of the Woven Fabric Liner. The woven fabric liner is mainly made up of matrix and reinforced fibers, and the fiber distribution of the typical woven fabric liners is shown in Figure 1. A global Cartesian coordinate system $(X, Y, Z)$ is set, where axis $X$, whose included angle with warp direction is $\beta$, is along the horizontal direction, and axes $Y, Z$ are along the directions of fill and thickness of the woven fabric liners, respectively. The angle between the warp and fill directions is $\gamma$, the fibers in the warp direction are the mixture of polytetrafluoroethylene (PTFE) and Nomex, and only Nomex fibres are in fill direction. The Nomex fiber is used to improve the strength of the liner materials and bonding properties, while the PTFE fiber is mainly used to improve friction and wear properties of materials. The matrix of the woven fabric liner is phenolic resin. 


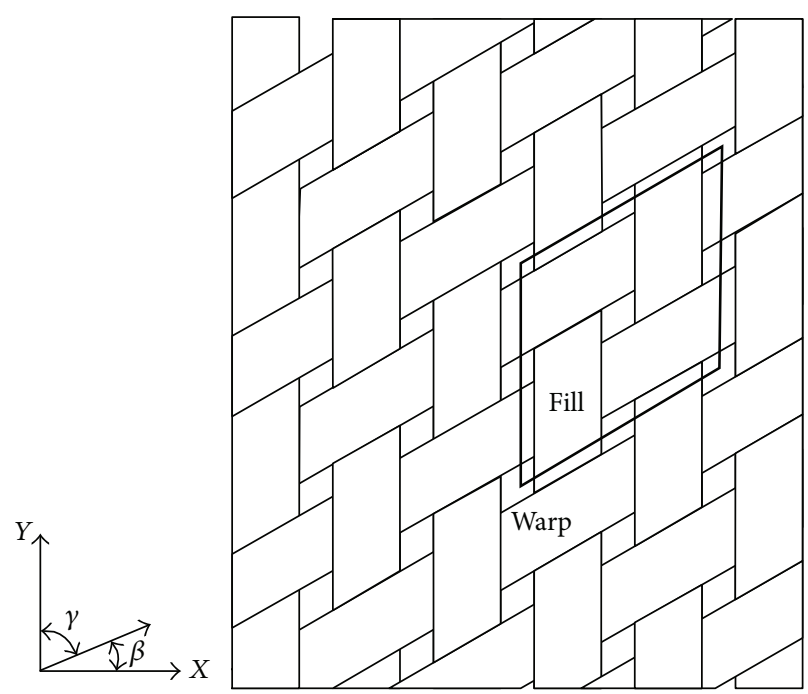

(a) Plain liner

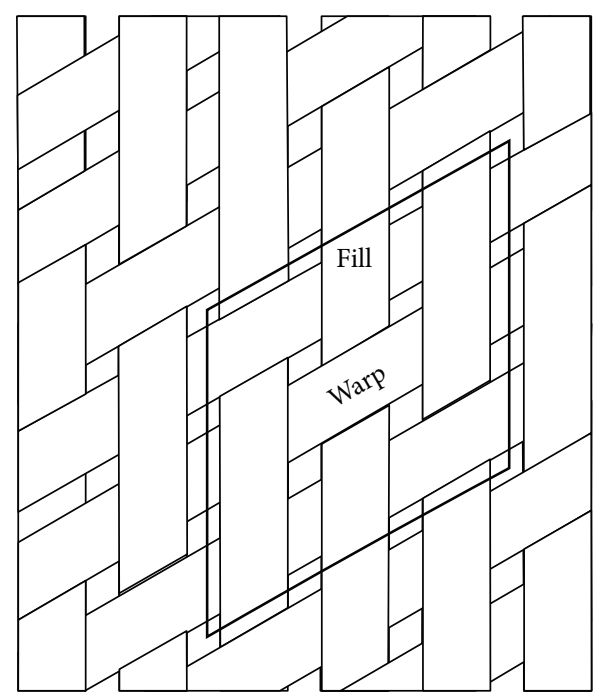

(b) Twill liner

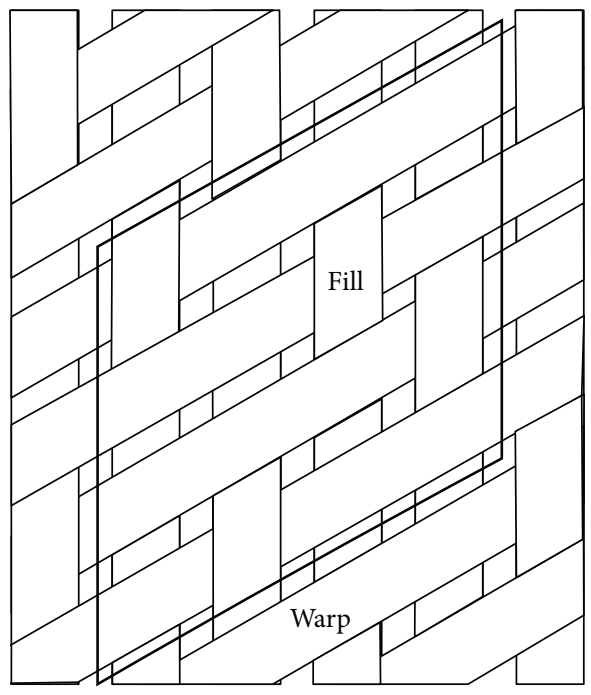

(c) Stain liner

Figure 1: Fiber distribution of the woven fabric liner.

Take the black box parts (in Figure 1) of the liners for the analysis units and make the following assumptions of the microstructure of the fabric liners.

(1) The cross section of the yarn is lenticular shape [15]. Its shape and geometric dimensions are shown in Figure 2.

The width $w_{w}$ and the thickness $d_{w}$ of the warp yarn after cutting along $Y$ direction can be obtained as

$$
w_{w}=\frac{w}{\sin \gamma}, \quad d_{w}=d,
$$

where $w$ and $d$ represent the width and the thickness of the yarn in the cross section, respectively. The subscript $w$ indicates the warp yarn, and the subscript $f$ will be used in the fill yarn (an exception if it is labeled especially). The warp yarns of the liner are taken as an example, to study here, and the fill yarns could be studied in the similar way.
The radius, $R_{w}$, the inner angle, $\varphi_{w}$, and the crosssectional area, $A_{w}$, can be expressed as follows:

$$
\begin{gathered}
R_{w}=\frac{w_{w}^{2}}{4 d_{w}}+\frac{d_{w}}{4}, \quad \varphi_{w}=2 \arcsin \left(\frac{2 w_{w} d_{w}}{d_{w}^{2}+w_{w}^{2}}\right), \\
A_{w}=R_{w}^{2} \varphi_{w}-w_{w} R_{w}+\frac{d_{w} w_{w}}{2} .
\end{gathered}
$$

(2) Warp and fill yarns have the same fiber directions.

The global coordinate system of the liner is $(X, Y, Z)$, the coordinate system of the plane of the fiber yarn trace is local coordinate system $(u, v, w)$, and the coordinate system of the fiber yarn trace is local coordinate system $(1,2,3)$. The local coordinate system $(u, v, w)$ is obtained by $\beta$ angle rotation of the global coordinate system $(X, Y, Z)$ around $Z$ axis, and the coordinate axes of $(1,2,3)$ is parallel to the axes of $(u, v, w)$ 


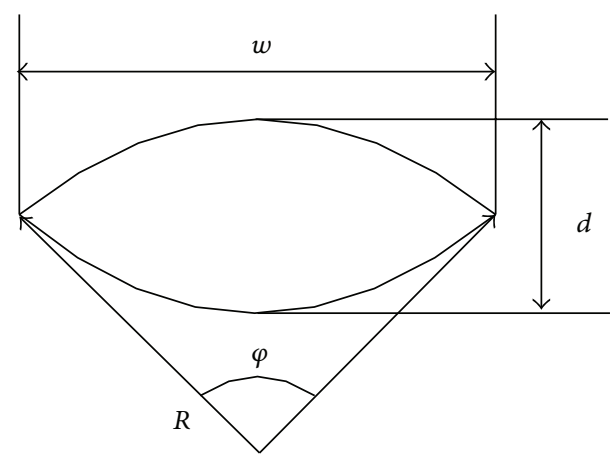

FIgURE 2: Cross section of the fiber yarn.

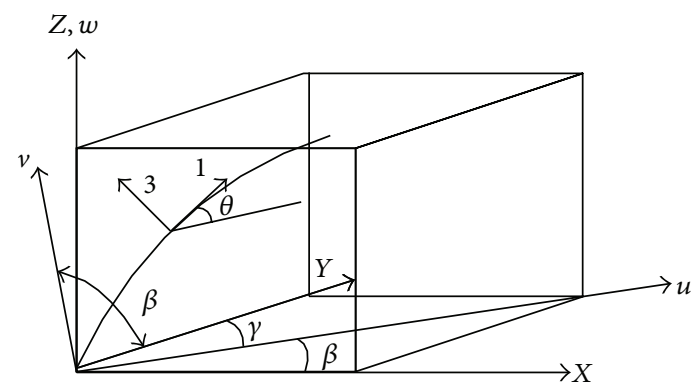

FIGURE 3: Coordinate systems of warp yarn.

after rotating $\theta$ angle around $v$ axis. The position relationship of the coordinate systems is shown in Figure 3.

Fibers directions are divided into the straight parts and the curve parts shown in Figure 4. This model applies to plain, twill, and stain fabric liners. as

The thickness of two layers of fiber yarns can be written

$$
t=d_{w}+d_{f},
$$

where $d_{f}$ indicates the thickness of the fill yarn after cutting along warp direction.

The bend radius of the yarn can be obtained as

$$
r_{w}=R_{f}+\frac{d_{w}}{2} .
$$

Yarn-to-yarn distance is

$$
L s_{w}=2 \sqrt{r_{w}^{2}-R_{f}^{2}} .
$$

The length of the curve part of the yarn is

$$
L c_{w}=r_{w} \varphi_{f} .
$$

The length of the warp yarn can be calculated by

$$
L_{s / w}=m L s_{w}+2 L c_{w}, \quad m=0,1,2,
$$

where $m=0,1,2$ represents plain, twill, and stain woven fabric liner, respectively. The subscript $s$ refers to the fiber yarn, the subscript $w$ refers to the warp direction, and the meaning of the subscript $s / w$ below is the same as here.

The volumes of the warp yarns in the basic study cell can be obtained as

$$
V_{s / w}=\sum_{i=1}^{n} A_{w i} L_{(s / w) i}, \quad n=2,3,4,
$$

where $n=2,3$, and 4 correspond to the plain, twill, and stain woven fabric liners, respectively. The meaning of the $n$ below is the same as here; $i=1$ represents the first warp yarn.

The length of the basic study cell in the warp direction can be written as

$$
L_{w}=n L s_{w}, \quad n=2,3,4 .
$$

The volume of the basic study cell is

$$
V=L_{w} L_{f} h,
$$

where $L_{f}$ indicates the length of the basic study cell in the fill direction, and $h$ represents the thickness of the study cell. Since the thickness of the matrix is very thin, we assume $h=t$.

The volume fraction of the warp yarns in the basic study cell can be obtained as

$$
v_{s / w}=\frac{V_{s / w}}{V} .
$$

The fiber volume fraction of the warp yarns can be written as

$$
\psi_{w}=\frac{k A_{f / w}}{A_{w}},
$$

where $k$ indicates the number of the single fiber in the yarn, $A_{f / w}$ represents the cross-sectional area of the single fiber, and subscripts $f$ and $w$ in $f / w$ refer to the single fiber and warp direction, respectively. The meaning of the subscript $f / w$ below is the same as here.

Accordingly, the fiber volume fraction of the warp direction in the basic study cell can be calculated by

$$
v_{f / w}=\psi_{w} v_{s / w}=\frac{k A_{f / w} \sum_{i=1}^{n} L_{(s / w) i}}{L_{w} L_{f} h}, \quad n=2,3,4 .
$$

2.2. Elastic Properties of the Woven Fabric Liner. The chamis model [16] is used to calculate the elastic constants of the straight part of the yarn. The expressions are as follows:

$$
\begin{gathered}
E_{11}=V_{f} E_{11}^{f}+V_{m} E^{m}, \quad v_{12}=V_{f} v_{12}^{f}+V_{m} \nu^{m}, \\
E_{22}=\frac{E^{m}}{1-\sqrt{V_{f}}\left(1-E^{m} / E_{22}^{f}\right)}, \\
G_{12}=\frac{G^{m}}{1-\sqrt{V_{f}}\left(1-G^{m} / G_{12}^{f}\right)}, \\
G_{23}=\frac{G^{m}}{1-\sqrt{V_{f}}\left(1-G^{m} / G_{23}^{f}\right)},
\end{gathered}
$$


where 1 is radial direction along the direction of the fiber axis; 2,3 are traverse directions lying in the plane perpendicular to the fiber; $E_{11}$ and $E_{22}$ are the elastic moduli of fiber yarn along the direction of 1 and 2, respectively; $v_{12}$ is Poisson's ratio of the fiber yarn of the 1-2 plane; $G_{12}$ and $G_{23}$ are the shear moduli of fiber yarn of the 1-2 and 2-3 planes, respectively; $E^{m}, v^{m}$, and $G^{m}$ are the elastic modulus, Poisson's ratio, and shear modulus of the matrix, respectively; $E_{11}^{f}, E_{22}^{f}, v_{12}^{f}$, $G_{12}^{f}$, and $G_{23}^{f}$ are the radial elastic modulus, traverse elastic modulus, in-plane Poisson's ratio, in-plane shear modulus, and 2-3 plane shear modulus of the fiber, respectively; $V_{f}$ indicates the fiber volume fraction of the yarn, namely, $\psi_{w}$ in the expression (12).

The curve part of the yarn can be regarded as the assemblage of a number of infinitesimal straight yarn segments. The compliance matrix of the straight part of the warp yarn in the local coordinate system $(1,2,3)$ and the transition matrix [16] between any two coordinate systems $\left(x_{1}, x_{2}, x_{3}\right)$ and $(x, y, z)$ can be written as

$$
S_{i j}^{s}=\left[\begin{array}{cccccc}
S_{11} & S_{12} & S_{12} & 0 & 0 & 0 \\
S_{12} & S_{22} & S_{23} & 0 & 0 & 0 \\
S_{12} & S_{23} & S_{22} & 0 & 0 & 0 \\
0 & 0 & 0 & S_{44} & 0 & 0 \\
0 & 0 & 0 & 0 & S_{55} & 0 \\
0 & 0 & 0 & 0 & 0 & S_{55}
\end{array}\right], \quad T=\left[\begin{array}{cccccc}
l_{1}^{2} & l_{2}^{2} & l_{3}^{2} & l_{2} l_{3} & l_{3} l_{1} & l_{1} l_{2} \\
m_{1}^{2} & m_{2}^{2} & m_{3}^{2} & m_{2} m_{3} & m_{3} m_{1} & m_{1} m_{2} \\
n_{1}^{2} & n_{2}^{2} & n_{3}^{2} & n_{2} n_{3} & n_{3} n_{1} & n_{1} n_{2} \\
2 m_{1} n_{1} & 2 m_{2} n_{2} & 2 m_{3} n_{3} & m_{2} n_{3}+m_{3} n_{2} & m_{1} n_{3}+m_{3} n_{1} & m_{1} n_{2}+m_{2} n_{1} \\
2 n_{1} l_{1} & 2 n_{2} l_{2} & 2 n_{3} l_{3} & l_{2} n_{3}+l_{3} n_{2} & l_{1} n_{3}+n_{1} l_{3} & l_{1} n_{2}+l_{2} n_{1} \\
2 l_{1} m_{1} & 2 l_{2} m_{2} & 2 l_{3} m_{3} & l_{2} m_{3}+l_{3} m_{2} & l_{1} m_{3}+l_{3} m_{1} & l_{1} m_{2}+l_{2} m_{1}
\end{array}\right] \text {, }
$$

where subscripts $i$ and $j$ in $S_{i j}^{s}$ refer to the row and column, respectively. For the transition matrix $T$,

$$
\begin{array}{r}
l_{i}=\cos \left(x_{i}, x\right), \quad m_{i}=\cos \left(x_{i}, y\right), \quad n_{i}=\cos \left(x_{i}, z\right) \\
i=1,2,3 .
\end{array}
$$

The compliance matrix of the straight part of the warp yarn in the local coordinate system $(1,2$, and 3$)$ can be completely determined by the chamis model, based on the relationship between compliance matrix and elastic constants. The transition matrix $T_{w 1}$ between the local coordinate system $(1,2$, and 3$)$ and $(u, v, w)$ and $T_{w 2}$ between the local coordinate system $(u, v, w)$ and the global coordinate system $(X, Y, Z)$ can be obtained according to transition matrix $T$. Then the compliance matrix of the warp yarn in the global coordinate system can be derived

$$
\begin{gathered}
S_{i j}^{s w}=T_{w 2} S_{i j}^{s} T_{w 2}^{T}, \quad S_{i j}^{c G}=T_{w 2} T_{w 1} S_{i j}^{s} T_{w 1}^{T} T_{w 2}^{T}, \\
S_{i j}^{c w}=\frac{1}{\theta} \int_{0}^{\theta} S_{i j}^{c G} d \theta,
\end{gathered}
$$

where $S_{i j}^{s w}, S_{i j}^{c G}$, and $S_{i j}^{c w}$ signify the compliance matrices of the straight part, curve part yarn segment, and curve part yarn in the global coordinate system $(X, Y, Z)$, respectively.

The compliance matrix of the warp yarn can be written as

$$
S_{i j}^{w}=\lambda_{s w} S_{i j}^{s w}+\lambda_{c w} S_{i j}^{c w},
$$

where $\lambda_{c w}=2 L_{C w} / L_{s / w}$ and $\lambda_{s w}=1-\lambda_{c w}$ indicate the length fractions of the curve part and the straight part, respectively.

The compliance matrix of the fill yarn $S_{i j}^{f}$ can be obtained in a similar way. Since the compliance matrices of the warp and fill yarns have been obtained, their stiffness matrices can also be obtained by inversing their compliance matrices. Then according to the volume fraction of the fibers in the warp and fill directions, the stiffness matrices of the woven fabric liners of spherical plain bearing with self-lubricating can be calculated by

$$
C_{i j}^{c}=v_{f / w} C_{i j}^{w}+v_{f / f} C_{i j}^{f}+\left(1-v_{f / w}-v_{f / f}\right) C_{i j}^{m},
$$

where $C_{i j}^{w}$, $C_{i j}^{f}$, and $C_{i j}^{m}$ indicate the stiffness matrices of the warp yarn, fill yarn, and matrix, respectively. $v_{f / w}$ and $v_{f / f}$ refer to fiber volume fraction of the warp and fill direction, respectively.

The compliance matrix $S_{i j}^{c}$ of the woven fabric liner can be obtained by inversing stiffness matrix $C_{i j}^{c}$, and the nine elastic constants of the liner can be written as $E_{11}=1 / S_{11}^{c}, E_{22}=$ $1 / S_{22}^{c}, E_{33}=1 / S_{33}^{c}, v_{12}=-S_{12}^{c} / S_{11}^{c}, v_{23}=-S_{23}^{c} / S_{22}^{c}, v_{13}=$ $-S_{13}^{c} / S_{11}^{c}, G_{12}=1 / S_{66}^{c}, G_{13}=1 / S_{55}^{c}$, and $G_{23}=1 / S_{44}^{c}$.

\section{Elastic Properties Test and Validation of the Analysis Model}

Experiment specimens include two types of woven fabric liners: one is the plain woven fabric liner with PTFE fibers in both the warp and fill directions; the other is the stain woven fabric liner with PTFE and Nomex fibers in the warp direction and Nomex fiber in the fill direction. The experiment is implemented by Zwick/Roell (BZ2.5/TS1S) test machine. During the experiment, the displacement control mode is used, and the loading speed is $0.2 \mathrm{~mm} / \mathrm{min}$. A CCD camera is placed at the normal of the specimen surface to record images while loading. Precision for strain measurement is $50 \mu \varepsilon$. The sequential images are subjected to DIC (digital image correlation) analysis, and then we can acquire the elastic properties of the liners through the corresponding 


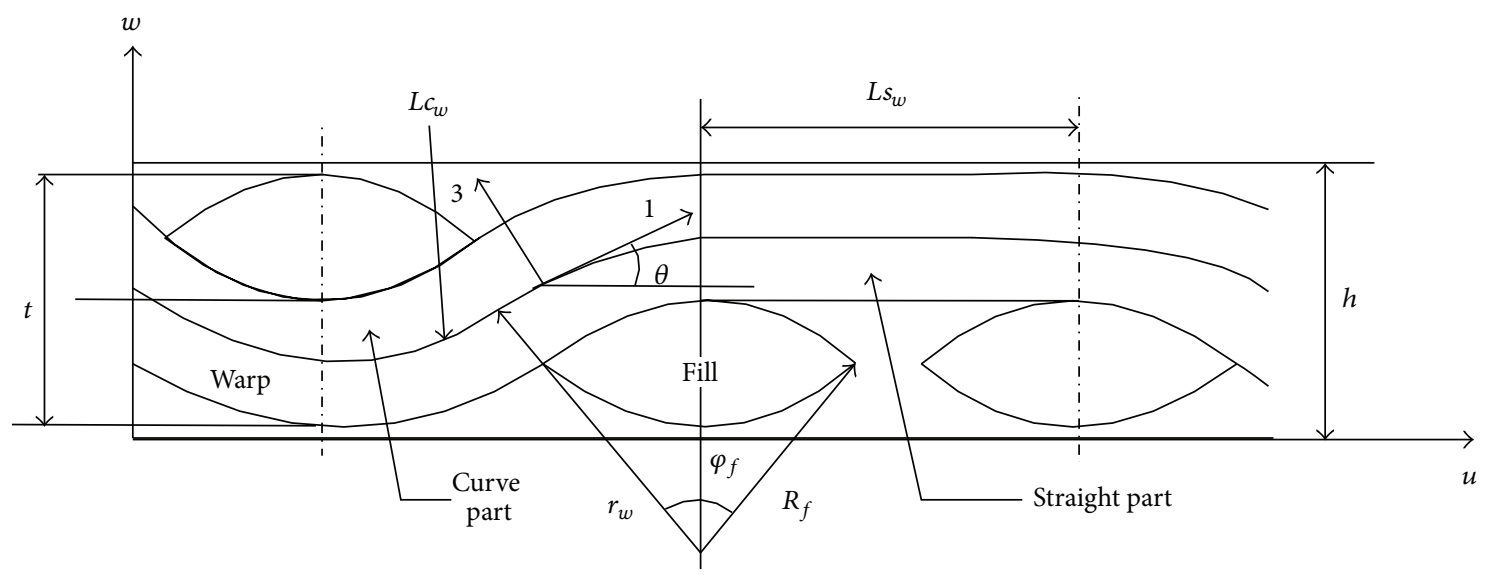

Figure 4: Geometric model of fibers directions.

TABLE 1: Geometric parameters of woven fabric composites.

\begin{tabular}{|c|c|c|c|c|c|c|c|}
\hline \multirow{2}{*}{ Liner types } & \multicolumn{2}{|c|}{ Thickness of yarn $(\mathrm{mm})(d)$} & \multicolumn{2}{|c|}{ Width of yarn $(\mathrm{mm})(w)$} & \multirow{2}{*}{$\begin{array}{l}\text { Lamina thickness } \\
\qquad(\mathrm{mm})(h)\end{array}$} & \multirow{2}{*}{$\begin{array}{l}\text { Inner angle }\left(^{\circ}\right) \\
\quad\left(\varphi_{w}\right)\end{array}$} & \multirow{2}{*}{$\begin{array}{l}\text { Fiber volume fraction of } \\
\text { the yarn }\left(\psi_{w}\right)\end{array}$} \\
\hline & Warp & Fill & Warp & Fill & & & \\
\hline Plain/stain liners & \multicolumn{2}{|c|}{0.19} & \multicolumn{2}{|c|}{0.51} & 0.38 & 90 & 0.70 \\
\hline
\end{tabular}

TABle 2: Material elastic properties.

\begin{tabular}{lccccc}
\hline Material & $E_{11}(\mathrm{GPa})$ & $E_{22}(\mathrm{GPa})$ & $G_{12}(\mathrm{GPa})$ & $G_{13}(\mathrm{GPa})$ & $\nu_{12}$ \\
\hline PTFE fiber & 0.75 & 0.75 & 0.28 & 0.28 & 0.30 \\
$\begin{array}{l}\text { Nomex fiber } \\
\begin{array}{l}\text { Phenolic resin } \\
\text { matrix }\end{array}\end{array}$ & 6.70 & 6.70 & 2.69 & 2.69 & 0.23 \\
\hline
\end{tabular}

stress-strain curves. The structural and material parameters are shown in Tables 1 and 2 [17]. The elastic properties of plain and stain liners can be calculated by applying the structural and material parameters to Sections 2.1 and 2.2, respectively. The comparison between the computational and experimental results is listed in Table 3. The coordinate system $(X, Y, Z)$ is replaced by $(1,2$, and 3$)$ to align with the conventional means of expression.

Table 3 shows that the calculation results of plain woven fabric liner are in good agreement with the experimental data. Relative error of the warp elastic modulus of the stain woven fabric liner is a little bit bigger, but within the scope of the engineering allowable error.

\section{Influence of Elastic Properties of the Liner on Wear Depth of Spherical Plain Bearing}

Wear simulation was realized by commercial finite element software ABAQUS. Wear simulation program is designed using Python language and the elastic properties of the liner is changed to derive the variation trend of the maximum wear depth of spherical plain bearing after 25000 cycles of oscillating.

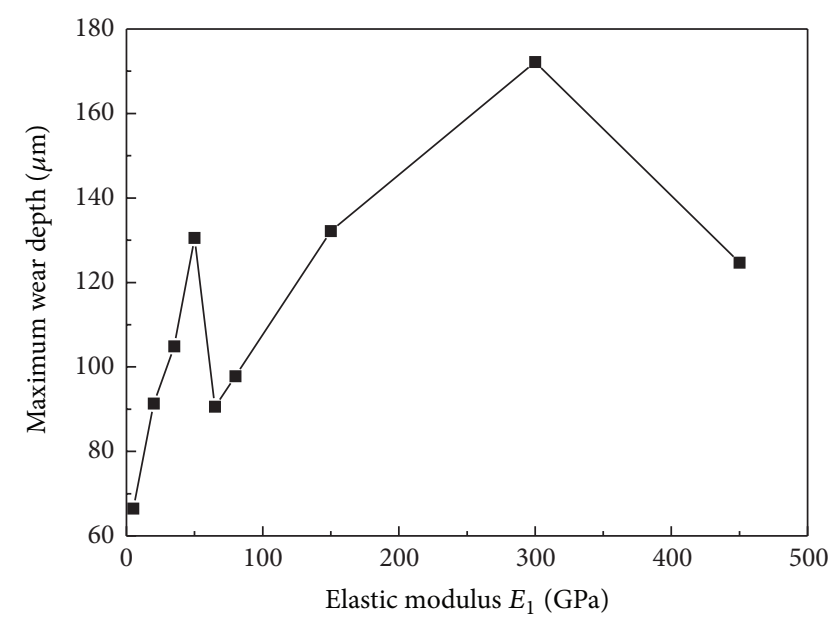

FIGURE 5: Influencing of elastic modulus $E_{1}$ on the maximum wear depth.

Figure 5 to Figure 8 are the curves of influencing of the elastic properties on the maximum wear depth of the spherical plain bearing after 25000 cycles of oscillating.

Figures 5 and 6 show that the elastic moduli of the liner have a tremendous impact on the maximum wear depth of the spherical plain bearing. The elastic moduli $E_{1}\left(E_{2}\right)$ and $E_{3}$ have an opposite influence on the maximal wear depth when they vary from $0 \mathrm{GPa}$ to $65 \mathrm{GPa}$. With $E_{1}\left(E_{2}\right)$ increasing, the maximal wear depth is firstly increased by $96.34 \%$ and then decreased by $30.61 \%$. With the increase of $E_{3}$, the maximal wear depth is firstly decreased by $49.31 \%$ and then increased by $28.33 \%$. When the elastic moduli are over $65 \mathrm{GPa}$, the maximal wear depth increases firstly and then decreases and increases with the increase of $E_{1}\left(E_{2}\right)$ and $E_{3}$, respectively. 
TABLE 3: Comparison between the computational and experimental results.

\begin{tabular}{lccrr}
\hline Liner types & Elastic properties & Computational results & Test results & 1.98 \\
Plain liner & $E_{11}(\mathrm{GPa})$ & 1.95 & 1.98 & $1.35 \%$ \\
& $E_{22}(\mathrm{GPa})$ & 1.95 & 0.63 & $1.35 \%$ \\
& $G_{12}(\mathrm{GPa})$ & 0.66 & 2.96 & $4.39 \%$ \\
\hline \multirow{3}{*}{ Stain liner } & $E_{11}(\mathrm{GPa})$ & 3.29 & 3.23 & $11.15 \%$ \\
& $E_{22}(\mathrm{GPa})$ & 3.36 & 1.09 & $4.02 \%$ \\
& $G_{12}(\mathrm{GPa})$ & 1.19 & $9.17 \%$ \\
\hline
\end{tabular}

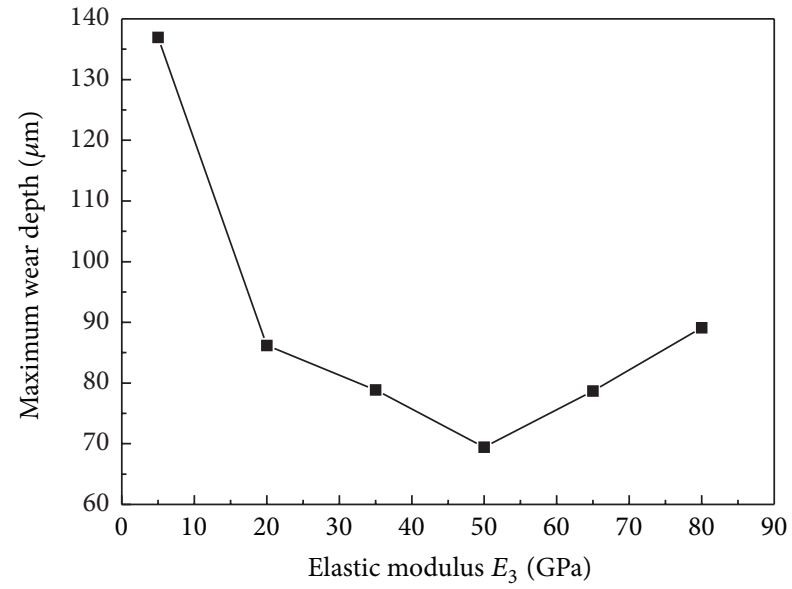

FIgURE 6: Influencing of elastic modulus $E_{3}$ on the maximum wear depth.

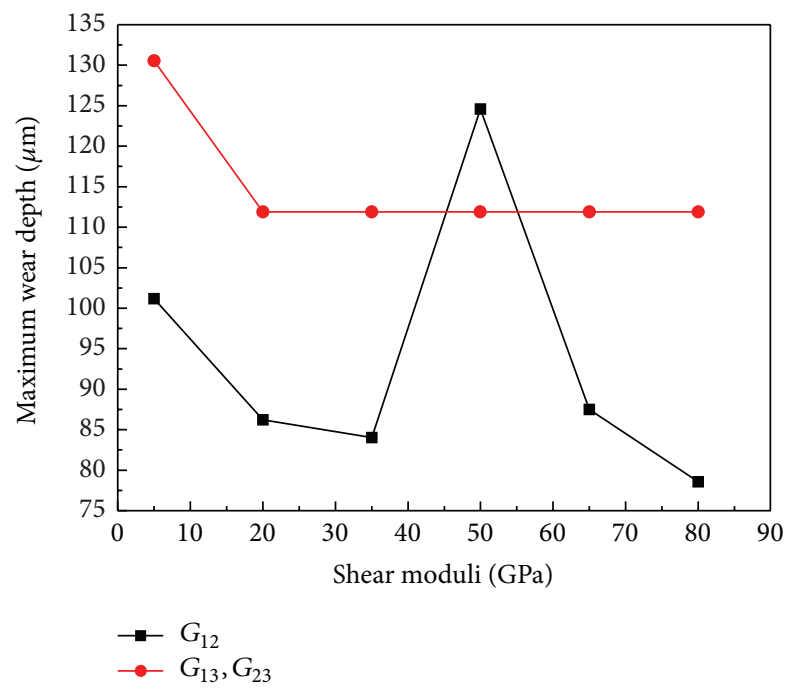

FIGURE 7: Influencing of shear moduli on the maximum wear depth.

The main movement pattern of the spherical plain bearing is multiaxial rotary oscillating motion in a lower speed, so there is an impact of the in-plane shear performance on wear depth of the spherical plain bearing, which cannot be ignored. As shown in Figure 7, with the shear modulus $G_{12}$ increasing, the maximal wear depth firstly decreases, then increases, and then decreases again. And it varies greatly when the shear

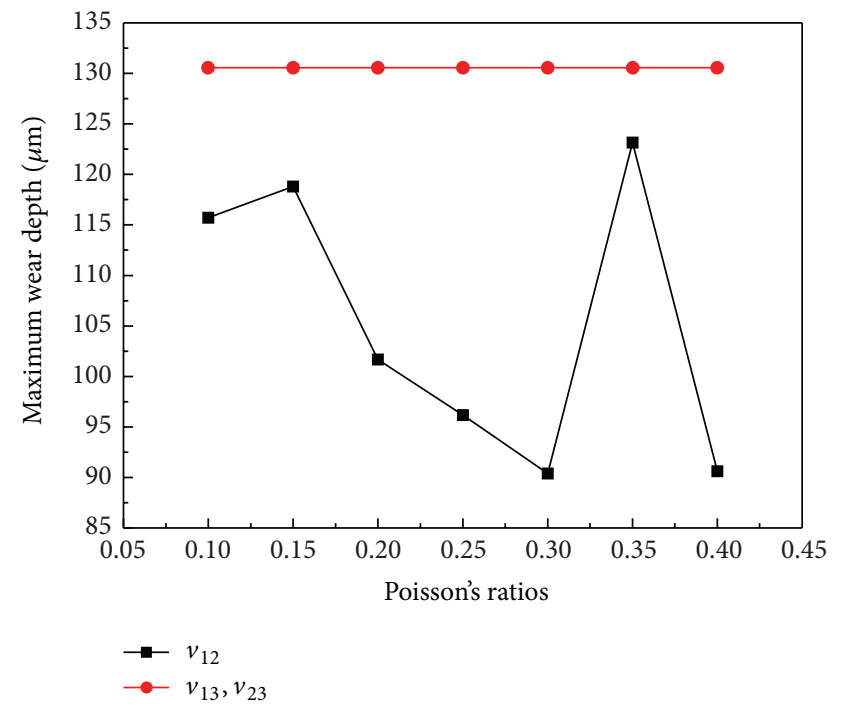

FIgURE 8: Influencing of Poisson's ratios on the maximum wear depth.

modulus $G_{12}$ ranges from $35 \mathrm{GPa}$ to $60 \mathrm{GPa}$. The maximal wear depth of the bearing almost keeps the same and is under the minimum state when $G_{13}$ and $G_{23}$ change from $20 \mathrm{GPa}$ to $80 \mathrm{GPa}$.

Figure 8 suggests that the maximum wear depth will increase and decrease when the Poisson's ratio $v_{12}$ increases in the area of 0.1 to 0.15 or 0.3 to 0.35 and 0.15 to 0.3 or 0.35 to 0.4 , respectively. The maximal wear depth will be minimal when Poisson's ratio $v_{12}$ is 0.3 . Poisson's ratios $v_{13}$ and $v_{23}$ have no effect on the maximal wear depth.

The wear depth of the spherical plain bearing at predetermined conditions cannot be greater than allowed limit $0.114 \mathrm{~mm}$ based on the standard MIL-B-81820. Thus the elastic moduli $E_{1}$ and $E_{2}$ should change from $0 \mathrm{GPa}$ to $40 \mathrm{GPa}$ or $56 \mathrm{GPa}$ to $113 \mathrm{GPa}, E_{3}$ should be greater than $12 \mathrm{GPa}$, the shear modulus $G_{12}$ should change from $0 \mathrm{GPa}$ to $46 \mathrm{GPa}$ or $54 \mathrm{GPa}$ to $80 \mathrm{GPa}$, and Poisson's ratios $\nu_{12}$ should change from 0.16 to 0.34 or 0.36 to 0.45 . Because the elastic constants $G_{13}$, $G_{23}, v_{13}$, and $v_{23}$, have a little or no influence on the maximal wear depth, they can be ignored.

\section{Conclusions}

An elastic property analysis model, which is suitable for three commonly used woven fabric liners, is described in 
this paper. The influence of the elastic properties on the wear depth of the spherical plain bearings is further investigated. The following is a summary.

(1) A general elastic properties analysis model adjusting to the plain, twill, and stain liners was built.

(2) For the plain woven fabric liner, the computational results of elastic properties are in good agreement with the experimental data, and the relative errors of in-plane elastic and shear moduli are $1.35 \%$ and $4.39 \%$, respectively. For the stain woven fabric liner, the relative error of the warp elastic modulus is $11.15 \%$, which is a little larger but within the scope of the engineering allowable error, and the relative errors of fill elastic and in-plane shear modulus are $4.02 \%$ and $9.17 \%$, respectively.

(3) The influence of the liner elastic properties on the wear of the spherical plain bearing was analyzed based on the finite element method. The results show that the liner elastic properties, which are the elastic moduli $E_{1}\left(E_{2}\right)$ and $E_{3}$, the shear modulus $G_{12}$, and Poisson's ratio $v_{12}$, have the greater impacts on the maximal wear depth of the woven fabric liner of the spherical plain bearing. The results also show that the shear moduli $G_{13}\left(G_{23}\right)$ have a small effect and Poisson's ratios $v_{13}\left(v_{23}\right)$ have no effect on the liner's wear.

(4) For the woven fabric liner of the spherical plain bearing based on the standard MIL-B-81820, the elastic moduli $E_{1}, E_{2}$ should change from $0 \mathrm{GPa}$ to $40 \mathrm{GPa}$ or $56 \mathrm{GPa}$ to $113 \mathrm{GPa}, E_{3}$ should be greater than $12 \mathrm{GPa}$, the shear modulus $G_{12}$ should change from $0 \mathrm{GPa}$ to $46 \mathrm{GPa}$ or $54 \mathrm{GPa}$ to $80 \mathrm{GPa}$, and Poisson's ratios $v_{12}$ should change from 0.16 to 0.34 or 0.36 to 0.45 , so as to meet the wear requirement of the bearing. The elastic constants $G_{13}, G_{23}, \nu_{13}$, and $v_{23}$ have a little or no influence on the maximal wear depth; therefore they can be ignored. Above suggestions could be used for the optimal design of the spherical plain bearings based on wear reduction, so as to select the suitable geometric and material parameters of the woven fabric composite.

\section{Conflict of Interests}

The authors declare that there is no conflict of interests regarding the publication of this paper.

\section{Acknowledgments}

This work is supported by the COSTIND of China (D.500109-11-002) and High and New Engineering Program of Shanghai (D.51-0109-09-001). The authors wish to thank Professor Q. Jane Wang at Northwestern University of USA for valuable discussions.

\section{References}

[1] B. C. Kim, D. C. Park, H. S. Kim, and D. G. Lee, "Development of composite spherical bearing," Composite Structures, vol. 75, no. 1-4, pp. 231-240, 2006.

[2] M. F. Fleszar, "Thermal behaviour of teflon/phenolic liners in self-lubricating bearings," Journal of Thermal Analysis, vol. 49, no. 1, pp. 219-226, 1997.

[3] D. Xiang, Z. Yao, and J. Wen, "Experimental investigation on dry frictional behavior of the two self-lubricating composites under heavy loading conditions," Materials Letters, vol. 59, no. 18, pp. 2352-2356, 2005.

[4] Q. Guo, Y.-F. Song, H.-B. Qiao, and W.-L. Luo, "The friction and wear properties of the spherical plain bearings with selflubricating composite linear in oscillatory movement," Journal of Wuhan University of Technology, vol. 19, pp. 86-91, 2004.

[5] B. j. Pang, S. Y. Du, J. C. Han, X. D. He, and Y. Yan, "Experimental investigation of three-dimensional four-directional braided carbon/epoxy composites," Acta Materiae Compositae Sinica, vol. 16, no. 4, pp. 136-141, 1999.

[6] C.-K. Yang, "Research of mechanical properties of 3D braided composite materials," Journal of Materials Engineering, no. 7, pp. 33-36, 2002.

[7] Z. Xia, C. Zhou, Q. Yong, and X. Wang, "On selection of repeated unit cell model and application of unified periodic boundary conditions in micro-mechanical analysis of composites," International Journal of Solids and Structures, vol. 43, no. 2, pp. 266-278, 2006.

[8] K. Xu and X. Xu, "Prediction of elastic constants and simulation of stress field of 3D braided composites based on the finite element method," Acta Materiae Compositae Sinica, vol. 24, no. 3, pp. 178-185, 2007.

[9] W.-Y. Zhang, Z.-H. Yao, X.-F. Yao, and Y.-P. Cao, "Numerical model of woven fabric composites," Engineering Mechanics, vol. 21, no. 3, pp. 55-60, 2004.

[10] P. Vandeurzen, J. Ivens, and I. Verpoest, "A three-dimensional micromechanical analysis of woven-fabric composites: I. Geometric analysis," Composites Science and Technology, vol. 56, no. 11, pp. 1303-1315, 1996.

[11] J. L. Kuhn and P. G. Charalambides, "Modeling of plain weave fabric composite geometry," Journal of Composite Materials, vol. 33, no. 3, pp. 188-220, 1999.

[12] T. C. Lim, "Elastic stiffness of three-phase composites by the generalized mechanics-of-materials (GMM) approach," Journal of Thermoplastic Composite Materials, vol. 15, no. 2, pp. 155-168, 2002.

[13] R. Wang, J.-K. Wang, and L. Wu, "Prediction for elastic properties of plain weave fabric composites," Acta Materiae Compositae Sinica, vol. 19, no. 1, pp. 90-94, 2002.

[14] L. Wang and Y. Yan, "Micro analysis and experimental study of the elastic properties of braided composites structure," Acta Materiae Compositae Sinica, vol. 21, no. 4, pp. 152-156, 2004.

[15] S.-K. Lee, J.-H. Byun, and S. H. Hong, "Effect of fiber geometry on the elastic constants of the plain woven fabric reinforced aluminum matrix composites," Materials Science and Engineering A, vol. 347, no. 1-2, pp. 346-358, 2003.

[16] Z. M. Huang, An Introduction to Micromechanics of Composites, The Press of Science, 2004.

[17] L. Deters, F. Mueller, and M. Berger, "Self-lubricating dry rubbing bearings-fundamentals and methods of calculation," Tribology Series, vol. 41, pp. 183-194, 2003. 

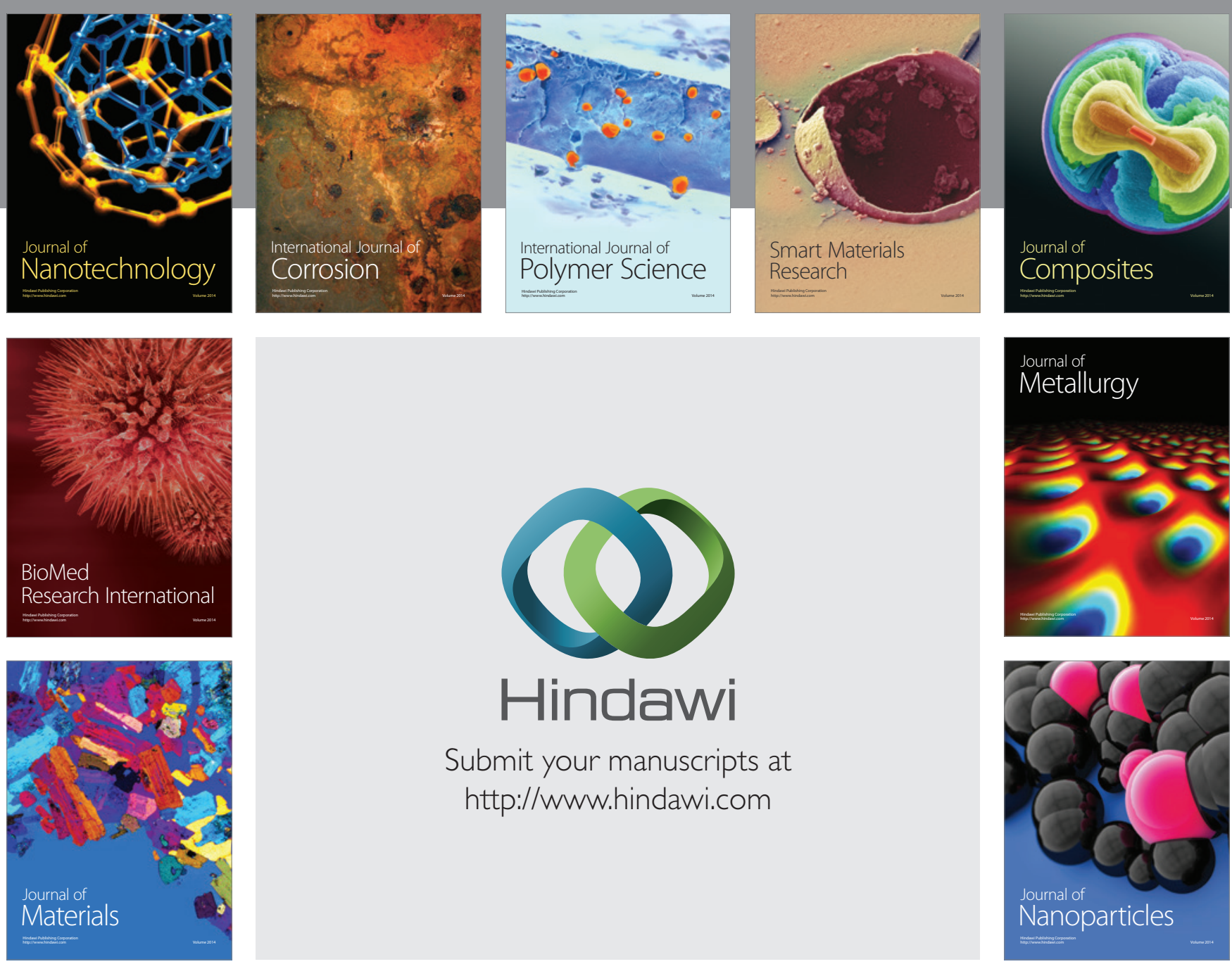

Submit your manuscripts at http://www.hindawi.com
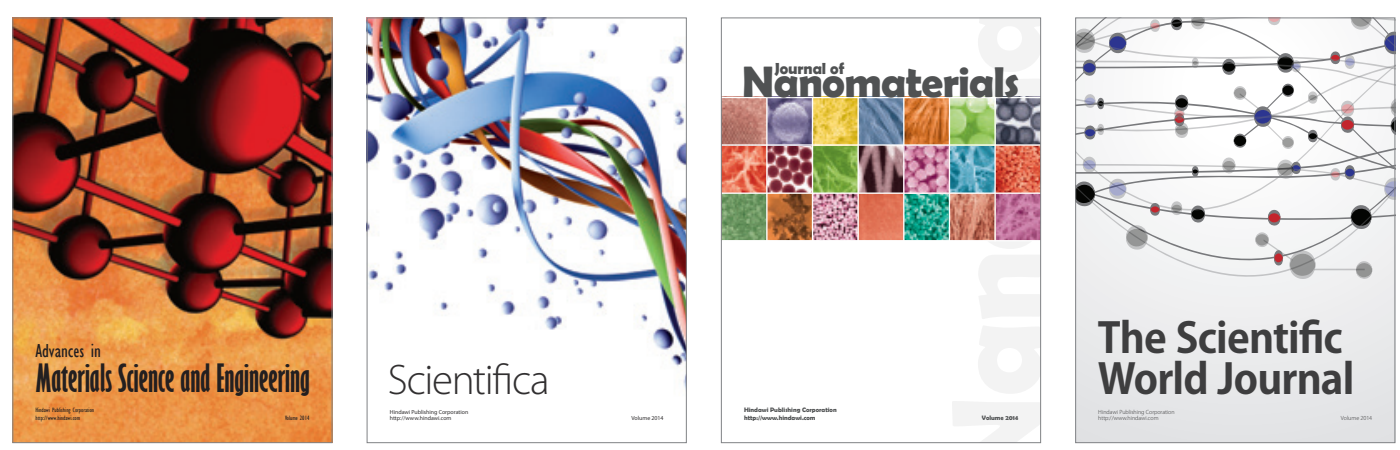

\section{The Scientific World Journal}
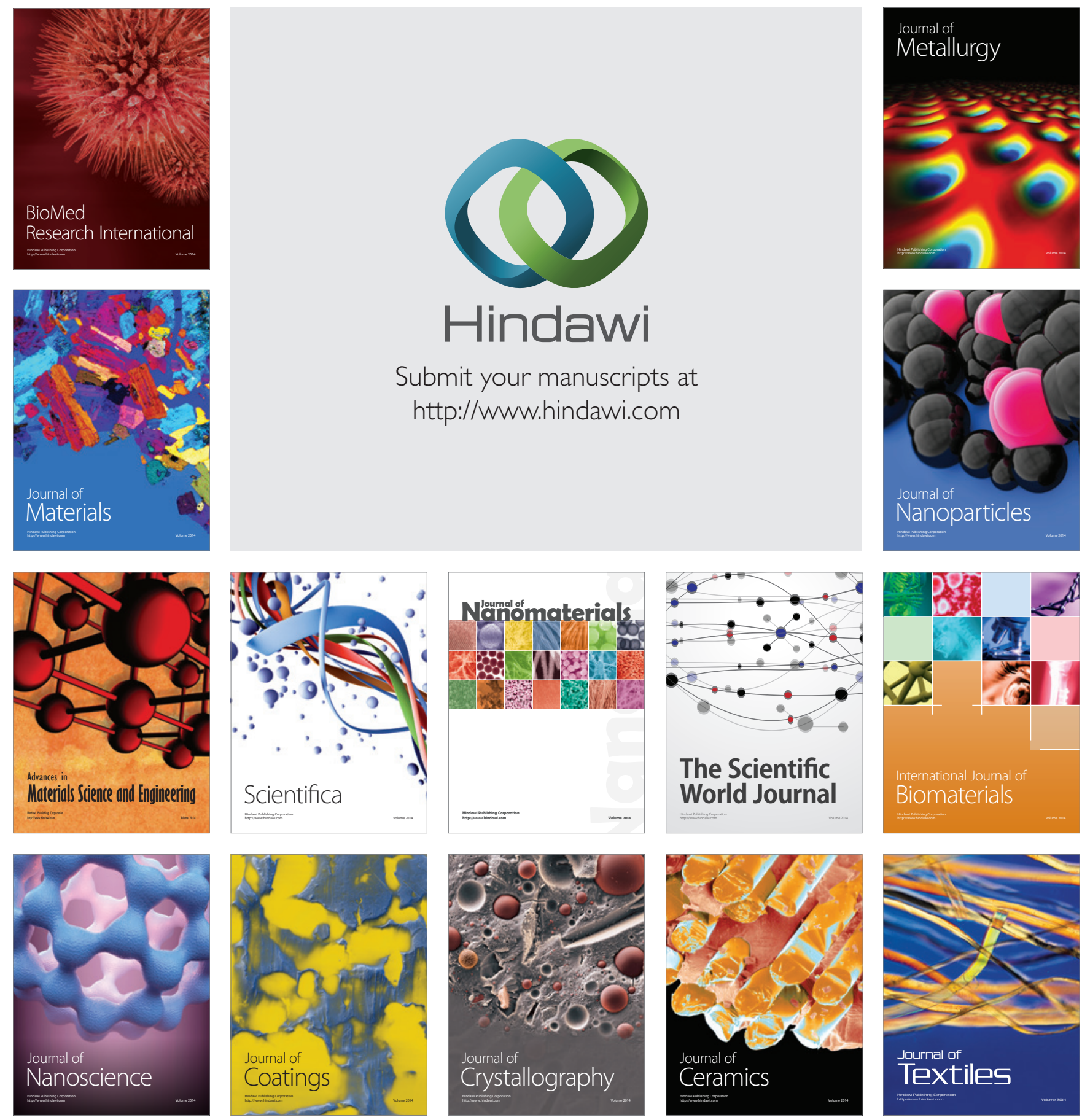